\title{
TRANSTORNO DO ESPECTRO AUTISTA E A QUALIDADE DE VIDA E ENFRENTAMENTO DOS FAMILIARES: UMA REVISÃO INTEGRATIVA
}

\author{
Amanda Barbosa da Silva ${ }^{1}$, Nathanielly Cristina Carvalho de Brito Santos ${ }^{2}$ \\ ${ }^{1}$ Curso de Bacharelado em Enfermagem, Unidade Acadêmica de Enfermagem, Universidade \\ Federal de Campina Grande, Cuité-PB, Brasil. \\ ${ }^{2}$ Prof ${ }^{a}$ Unidade Acadêmica de Enfermagem, Universidade Federal de Campina Grande, Cuité, \\ PB, Brasil. \\ Email para correspondência: amanda-bs1@live.com
}

\begin{abstract}
Resumo
O Transtorno do Espectro Autista é uma síndrome neuropsiquiátrica, com causa desconhecida, desenvolvimento multifatorial e diagnóstico clínico. Surge nos primeiros três anos, apresentando dificuldades de comunicação, interação social, comportamentos esteriotipados e apego por rotinas. Exige um processo de adaptação da dinâmica familiar. Objetivou-se sumarizar o que a literatura apresenta sobre qualidade de vida e estratégias de enfrentamento dos pais/familiares de crianças com transtorno do espectro autista no período de 2014 - 2019?. Trata-se de uma pesquisa qualitativa, tipo revisão integrativa, realizada na Biblioteca Virtual em Saúde, base de dados Medical Literature Analysis and Retrieval System Online em março de 2019. Os Descritores em Ciência da Saúde utilizados foram Adaptation Psychological, Quality of Life, Family e Autism Spectrum Disorder cruzados com o operador booleano $A N D$. Foram selecionados 4 artigos e à análise de conteúdo, elencadas duas categorias temáticas: Qualidade de vida, visto as implicações, pressões, cobranças internas e externas, que alteram o funcionamento familiar; e Estratégias de enfrentamento, atitudes diante dificuldades e a contribuição disso para melhoria na qualidade de vida dessa pessoa. Assim, a melhoria na qualidade de vida dos familiares parte das formas de enfrentamento como disparadores na busca por suprirem as demandas da criança, mas também as suas.
\end{abstract}

Palavras-chave: Transtorno do Espectro Autista, Qualidade de Vida, Estratégias de Enfrentamento, Familia, Enfermagem.

\section{Abstract / resumen / résumé}

Autistic Spectrum Disorder is a neuropsychiatric syndrome, with unknown cause, multifactorial development and clinical diagnosis. It appears in the first three years, presenting difficulties in communication, social interaction, stereotyped behaviors and attachment to routines. It requires a process of adapting the family dynamics. The objective was to summarize what the literature presents about quality of life and coping strategies of parents / family members of children with autism spectrum disorder in the period 2014 - 2019 ?. This is a qualitative research, like an integrative 
review, carried out at the Virtual Health Library, Medical Literature Analysis and Retrieval System Online database in March 2019. The Health Science Descriptors used were Adaptation Psychological, Quality of Life, Family and Autism Spectrum Disorder crossed with the Boolean operator AND. Four articles were selected and the content analysis included two thematic categories: Quality of life, considering the implications, pressures, internal and external demands, which alter family functioning; and Coping strategies, attitudes in the face of difficulties and the contribution of this to improving that person's quality of life. Thus, the improvement in the quality of life of family members starts from the forms of coping as triggers in the search for meeting the child's demands, but also yours.

Keywords: Autistic Spectrum Disorder, Quality of Life, Coping Strategies, Family. Nursing

\section{Introdução}

O transtorno do espectro autista (TEA) é uma síndrome neuropsiquiátrica, que se desenvolve na infância, com os primeiros sinais até os três anos de idade, relacionados a déficits comportamentais, dificuldade de comunicação, interação social, padrão de comportamentos estereotipados e apego por rotinas. Embora as causas sejam desconhecidas, tem-se acreditado que o desenvolvimento do transtorno seja multifatorial, associado a fatores genéticos e neurobiológicos (ONZI; DE FIGUEIREDO GOMES, 2015).

Nesse sentido, o diagnóstico do TEA é clinico por meio de instrumentos específicos, que direcionam a observação de comportamentos da criança, bem como a entrevista com os pais. É importante ressaltar que a confirmação diagnóstica traz uma série de implicações e mudanças na rotina familiar, na qual a criança passa a ser o centro dos cuidados, exigindo um olhar mais amplo e atento de uma equipe multiprofissional para as suas necessidades (CANUT,2014).

Devido a essa especificidade, os familiares de crianças com TEA acabam sendo mais propensos a desenvolverem problemas de saúde mental e altos níveis de estresse parental. Conviver com uma criança com necessidades especiais, exige redirecionamento do tempo para o cuidado e desempenho da mesma, exigindo um processo de adaptação da dinâmica familiar o que pode afetar a qualidade de vida com sobrecargas emocionais e ansiedade (SANTOS; PEREIRA-MARTINS, 2016).

Ademais, limitações na assistência de qualidade e no acesso à educação, bem como cobrança pelos familiares frente a condição da criança, geram nos pais uma necessidade de encontrar estratégias para este enfrentamento (JOOSTEN; SAFE et al., 2014). 
Ante o exposto, e reconhecendo a importância de um olhar voltado para os pais/familiares de criança com TEA emergiu a seguinte questão norteadora: "Quais as evidências disponíveis na literatura sobre a qualidade de vida e estratégias de enfrentamento dos pais/familiares de crianças com transtorno do espectro autista, com potencial para contribuir para as práticas baseadas em evidências (PBE)?". Para responder ao questionamento diante do estado atual do conhecimento do tópico de interesse, bem como a identificação de lacunas que direcionam para o desenvolvimento de futuras pesquisas, traçou-se como objetivo: sumarizar o que a literatura apresenta sobre a qualidade de vida e estratégias de enfrentamento dos pais/familiares de crianças com transtorno do espectro autista no período de 2014 - 2019?

\section{Metodologia}

Trata-se de pesquisa descritiva, qualitativa, do tipo revisão integrativa da literatura, realizada a partir de um levantamento de estudos organizados e ordenados na Biblioteca Virtual em Saúde (BVS), com seleção na base Medical Literature Analysis and Retrieval System Online (MEDLINE).

Para realização da pesquisa foram seguidas sete etapas requeridas na revisão integrativa correlacionada entre si: 1) Identificação da questão norteadora, a saber: $\mathrm{O}$ que a literatura apresenta sobre a qualidade de vida $\mathrm{e}$ estratégias de enfrentamento dos pais/familiares de crianças com transtorno do espectro autista no período de 2014 - 2019?; 2) Seleção e consulta dos descritores, 3) Pesquisa na base de dados utilizando o cruzamento dos descritores pelo operador booleano AND, 4) Estabelecimento dos critérios de inclusão e exclusão, 5) Avaliação dos arquivos incluídos, 6) Interpretação dos Resultados e 7) Apresentação da revisão dos artigos.

A coleta de dados ocorreu no mês de março de 2019, para a qual utilizouse os descritores exatos cadastrados nos Descritores em Ciência e Saúde (DeCS): Family, Adaptation Psychological, Quality of Life e Autism Spectrum Disorder. Como critérios de inclusão foram validadas publicações indexadas no período de 2014 a 2019; nos idiomas: inglês, português e espanhol; e que versassem sobre temática em questão. Foram excluídos aqueles que se 
apresentavam indisponíveis para leitura na íntegra restritos à download mediante pagamento, e que fossem literatura cinzenta como teses, dissertações e manuais técnicos.

No primeiro momento foi realizado o cruzamento dos descritores Adaptation Psychological, Family e Autism Spectrum Disorder, utilizando-se o operador booleano AND, sendo obtidos 150 artigos, e destes, 120 na base de dados Medline. Após utilização dos filtros dentre os critérios de inclusão e exclusão, foram selecionados 74 artigos. Na sequência, realizou-se a leitura do título e resumo do artigo, o que resultou em 28 arquivos selecionados para leitura na íntegra. No entanto, 20 não estavam disponíveis na íntegra e 5 não atendiam a questão norteadora, sendo, portanto, apenas 3 artigos selecionados para análise.

No segundo momento foram cruzados os descritores Quality of Life, Family e Autism Spectrum Disorder também se utilizando o operador booleando AND. A busca resultou em 122 artigos, sendo 104 na base de dados Medline. Após serem submetidos os critérios de inclusão e exclusão da primeira busca, foram selecionados 34 artigos para leitura do título e resumo, que resultou em 7 artigos para leitura na íntegra. Todavia, 6 só estavam disponíveis mediante pagamento, o que resultou em apenas 1 artigo para análise.

Ante do exposto, o corpus da pesquisa foi composto de 4 artigos, que foram analisados a partir da análise de conteúdo (Bardin, 2011), que utiliza procedimentos sistemáticos e objetivos de descrição do conteúdo das mensagens, a partir de três etapas: pré-análise (determina os documentos que constituirão o corpus a ser analisado, em que formulam-se hipóteses e elaboramse indicadores que norteiam a interpretação final); a segunda é a exploração do material (codifica e categoriza utilizando o critério semântico, construindo desta forma categorias temáticas); a última etapa é o tratamento dos resultados: (temse a inferência e interpretação, sendo guiadas pela reflexão com embasamento nos materiais empíricos e confronto entre o conhecimento adquirido e 0 acumulado). 


\section{$3 \quad$ Resultados}

Percebe-se que os resultados evidenciados nesta revisão podem auxiliar 0 profissional na tomada de decisão na prática clínica e, consequentemente, a melhoria do cuidado.

O quadro 1 apresenta a caracterização dos artigos selecionados.

Quadro 1: Caracterização dos artigos selecionados na MEDLINE

\begin{tabular}{|c|c|c|c|c|}
\hline $\begin{array}{l}\text { Autor/ } \\
\text { Ano }\end{array}$ & Revista & Título & Objetivos & $\begin{array}{c}\text { Resultados/ } \\
\text { Conclusão }\end{array}$ \\
\hline $\begin{array}{l}\text { Gomes et } \\
\text { al., } 2015\end{array}$ & $\begin{array}{l}\text { Jornal de } \\
\text { pediatria }\end{array}$ & $\begin{array}{l}\text { Autismo no } \\
\text { Brasil: uma } \\
\text { revisão } \\
\text { sistemática da } \\
\text { família, desafios } \\
\text { e estratégias de } \\
\text { enfrentamento. }\end{array}$ & $\begin{array}{l}\text { Descrever } \\
\text { os desafios } \\
\text { encontrados } \\
\text { pelas } \\
\text { famílias na } \\
\text { convivência } \\
\text { com } \\
\text { crianças } \\
\text { portadoras } \\
\text { de } \\
\text { transtorno } \\
\text { do espectro } \\
\text { autista } \\
\text { (TEA) no } \\
\text { Brasil e as } \\
\text { estratégias } \\
\text { de } \\
\text { superação } \\
\text { empregadas }\end{array}$ & $\begin{array}{l}\text { Os desafios } \\
\text { encontrados } \\
\text { pelas famílias } \\
\text { foram: deficiente } \\
\text { acesso ao } \\
\text { serviço e apoio } \\
\text { social, escassez } \\
\text { de atividades de } \\
\text { lazer e } \\
\text { educacionais, } \\
\text { situação } \\
\text { financeira e } \\
\text { postergação } \\
\text { diagnostica, onde } \\
\text { as estratégias de } \\
\text { enfrentamento } \\
\text { foram: crenças } \\
\text { religiosas, acesso } \\
\text { a atendimento } \\
\text { médico e } \\
\text { multidisciplinar, } \\
\text { que contribuem } \\
\text { para a diminuição } \\
\text { de sobrecarga } \\
\text { dos cuidadores, } \\
\text { busca por apoio } \\
\text { social, } \\
\text { planejamento de } \\
\text { metas e acesso a } \\
\text { lazer. Sendo } \\
\text { assim, o convívio } \\
\text { inicial da criança } \\
\text { e dos pais com o } \\
\text { diagnóstico, } \\
\text { exige } \\
\text { reestruturação } \\
\text { familiar, o que }\end{array}$ \\
\hline
\end{tabular}




\begin{tabular}{|c|c|c|c|c|}
\hline & & & & $\begin{array}{l}\text { muitas vezes } \\
\text { sobrecarrega } \\
\text { emocional e } \\
\text { fisicamente todos } \\
\text { os membros da } \\
\text { família, os quais } \\
\text { precisaram de } \\
\text { formas de } \\
\text { enfrentamento } \\
\text { diante o fato. }\end{array}$ \\
\hline $\begin{array}{l}\text { Joosten; } \\
\text { Safe et } \\
\text { al., } 2014\end{array}$ & $\begin{array}{l}\text { Australian } \\
\text { Occupation } \\
\text { al Therapy } \\
\text { Journal }\end{array}$ & $\begin{array}{l}\text { Estratégias de } \\
\text { gestão de mães } \\
\text { de crianças em } \\
\text { idade escolar } \\
\text { com autismo: } \\
\text { Implicações } \\
\text { para a prática. }\end{array}$ & $\begin{array}{l}\text { Explorar as } \\
\text { estratégias } \\
\text { utilizadas } \\
\text { pelas mães } \\
\text { para } \\
\text { administrar } \\
\text { seus papéis } \\
\text { e emoções e } \\
\text { os } \\
\text { comportame } \\
\text { ntos de seus } \\
\text { filhos. }\end{array}$ & $\begin{array}{l}\text { As estratégias } \\
\text { utilizadas pelas } \\
\text { mães foram: se } \\
\text { manter positivo e } \\
\text { focar nas } \\
\text { potencialidades } \\
\text { de seu filho, } \\
\text { quando os } \\
\text { serviços de } \\
\text { terapia não } \\
\text { estavam } \\
\text { disponíveis as } \\
\text { próprias mães } \\
\text { assumiam o } \\
\text { papel de } \\
\text { terapeuta de } \\
\text { seus filhos, } \\
\text { saídas criativas, } \\
\text { com parceiros e } \\
\text { amigos para } \\
\text { relaxar, outra } \\
\text { estratégia foi } \\
\text { deixar suas } \\
\text { necessidades de } \\
\text { lado e priorizar a } \\
\text { de seu filho, o } \\
\text { que as mães } \\
\text { apresentaram } \\
\text { grande satisfação } \\
\text { nesse feito. } \\
\text { Notasse o estado } \\
\text { de resiliência, } \\
\text { onde essas mães } \\
\text { se veem mais } \\
\text { fortes vendo o } \\
\text { bem-estar de } \\
\text { seus filhos } \\
\text { mesmo que isto } \\
\text { custe o seu. }\end{array}$ \\
\hline
\end{tabular}




\begin{tabular}{|c|c|c|c|c|}
\hline $\begin{array}{l}\text { Kim et al., } \\
2018\end{array}$ & $\begin{array}{l}\text { Internationa } \\
\text { I journal of } \\
\text { qualitative } \\
\text { studies on } \\
\text { health and } \\
\text { well-being }\end{array}$ & $\begin{array}{l}\text { Ouvindo o } \\
\text { sussurro } \\
\text { gritando: uma } \\
\text { voz de mães } \\
\text { cuidadoras de } \\
\text { crianças com } \\
\text { autismo } \\
\text { distúrbio do } \\
\text { espectro (ASD). }\end{array}$ & $\begin{array}{l}\text { Compreend } \\
\text { er o lazer e } \\
\text { comportame } \\
\text { ntos } \\
\text { associados } \\
\text { a restrições } \\
\text { de lazer } \\
\text { entre estas } \\
\text { mães } \\
\text { cuidadoras. } \\
\text { Esta é uma } \\
\text { lacuna no } \\
\text { conheciment } \\
\text { o } \\
\text { relacionado } \\
\text { aos } \\
\text { comportame } \\
\text { ntos de lazer } \\
\text { entre as } \\
\text { mães que } \\
\text { crianças } \\
\text { com } \\
\text { transtorno } \\
\text { do espectro } \\
\text { autista } \\
\text { (ASD). }\end{array}$ & $\begin{array}{l}\text { A prática de } \\
\text { exercícios é a } \\
\text { estratégia de } \\
\text { enfrentamento } \\
\text { mais eficaz } \\
\text { devido a } \\
\text { possibilidade de } \\
\text { extravasamento } \\
\text { das emoções, } \\
\text { oferta de } \\
\text { atividades } \\
\text { recreativas mais } \\
\text { estruturadas } \\
\text { envolvendo toda } \\
\text { a família, ao } \\
\text { invés de focar na } \\
\text { sua própria } \\
\text { satisfação, } \\
\text { preferem dar } \\
\text { prioridade aos } \\
\text { seus filhos, no } \\
\text { qual o artigo } \\
\text { também expõe a } \\
\text { preferência das } \\
\text { mães pela } \\
\text { satisfação do seu } \\
\text { filho. }\end{array}$ \\
\hline $\begin{array}{l}\text { Pisula; } \\
\text { Porebowi } \\
\text { cz- } \\
\text { dörsmann } \\
\text {, } 2017\end{array}$ & PloS one & $\begin{array}{l}\text { Funcionamento } \\
\text { familiar, } \\
\text { estresse } \\
\text { parental e } \\
\text { qualidade de } \\
\text { vida em mães e } \\
\text { pais de crianças } \\
\text { polonesas com } \\
\text { autismo de alto } \\
\text { funcionamento } \\
\text { ou Síndrome de } \\
\text { Asperger }\end{array}$ & $\begin{array}{l}\text { Investigar a } \\
\text { percepção } \\
\text { do } \\
\text { funcionamen } \\
\text { to familiar } \\
\text { em pais de } \\
\text { crianças } \\
\text { com } \\
\text { transtornos } \\
\text { do } \\
\text { espectro do } \\
\text { autismo } \\
\text { (ASD) com } \\
\text { inteligência } \\
\text { faixa normal } \\
\text { e as } \\
\text { relações } \\
\text { entre o } \\
\text { funcionamen } \\
\text { to familiar, } \\
\text { estresse } \\
\text { parental e }\end{array}$ & $\begin{array}{l}\text { O estudo mostra } \\
\text { fatores que } \\
\text { influenciam para } \\
\text { uma baixa } \\
\text { qualidade de vida } \\
\text { como: dificuldade } \\
\text { de comunicação } \\
\text { entre pais e filhos } \\
\text { o que bloqueia as } \\
\text { relações } \\
\text { familiares, } \\
\text { dificuldades em } \\
\text { prestar atenção } \\
\text { nos outros } \\
\text { membros da } \\
\text { família e em } \\
\text { satisfazer suas } \\
\text { próprias } \\
\text { necessidades, } \\
\text { dificuldades } \\
\text { financeiras e a } \\
\text { pressão que é ter }\end{array}$ \\
\hline
\end{tabular}




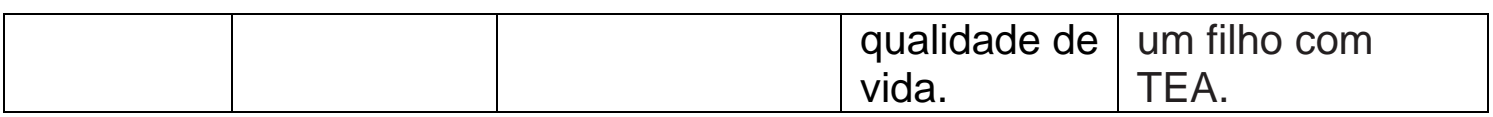

Fonte: Dados da pesquisa, 2019.

Os dados analisados conduziram a duas categorias temáticas, "Qualidade de vida" e "Estratégias de enfrentamento".

\subsubsection{Qualidade de Vida}

A qualidade de vida está amplamente ligada com o funcionamento familiar. Desse modo, ter ou cuidar de uma criança com TEA implica em pressões e cobranças tanto internas quanto externas, as quais geram conflitos entre os pais e ou cuidadores, pois afeta o senso de competência entre eles, causando uma maior carga de estresse (PISULA; POREBOWICZ-DÖRSMANN, 2017).

Somando-se ao fator cobrança, emerge a dificuldade de prestar atenção em outros membros da família, uma vez que os olhares estão direcionados as necessidades da criança com TEA. Assim, a comunicação com os outros membros da família torna-se limitada, o que desencadeia um distanciamento nas relações que deveriam ser a base de um funcionamento familiar sólido (PISULA; POREBOWICZ-DÖRSMANN, 2017).

Corroborando essa assertiva, estudo evidenciou que essa dedicação traz sobrecarga física e emocional, tanto diante dos cuidados gerais do filho com TEA, quanto das outras tarefas diárias, como os cuidados com a casa, e principalmente, com a atenção aos outros integrantes da família (CONSTANTINIDIS; SILVA; RIBEIRO, 2018).

Diante da sobrecarga física e emocional, cabe ressaltar que a repetição e monotonia de uma rotina semiestruturada para suprir com as demandas existentes da pessoa com autismo, pode gerar consequências emocionais com impacto diário para o cuidador (pais), por se colocarem em segundo plano e não satisfazerem suas próprias necessidades, o que pode gerar diminuição de bem (JOOSTEN; SAFE et al., 2014; PISULA; PORĘBOWICZ-DÖRSMANN, 2017).

Em função das exigências e permanente dependência da criança, todo o cotidiano das famílias fica voltado para a mesma. A dinâmica domiciliar, as atividades diárias, as rotinas de horário, independentemente da singularidade de 
cada integrante da família, são alteradas para poder dar o suporte e o cuidado necessário a criança, o que pode ocasionar alterações nas relações sociais vivenciadas pelos pais em seu cotidiano (MINATEL; MATSUKURA, 2014).

\subsubsection{Estratégias de enfrentamento}

Diante das dificuldades enfrentadas pelos cuidadores ou pais de crianças com espectro autista percebe-se que as estratégias elaboradas baseam-se nas necessidades de mudança da criança e suas singulariades. Assim, os pais focam em manter-se positivos diante das potencialidades e habilidades da criança, pois a cada dia existe uma nova descoberta em realação ao seu desenvolvimento (JOOSTEN; SAFE, 2014).

Esse resultado corrobora com estudo Machado, Londero; Pereira (2018), o qual demonstrou que aceitar a condição do filho com positividade, contribui para que a mãe possa submeter-se às exigências da condição da criança, e focar no desenvolvimento comportamental, e construir maneiras de idealiza-la novamente.

Nesse sentido, e diante as dificuldades de acesso aos serviços de saúde disponiveis, uma forma de enfrentar a falta de assistência, é desempenhando um papel que não é seu, pois na maioria das vezes as familias não dispõem de boas condições financeiras e para que não falte esse cuidado, são obrigados a abidicar de algumas coisas em favor do bem estar da criança (JOOSTEN; SAFE et al., 2014).

É pertinente ressaltar que as mães agem de forma objetiva e prática, tomando iniciativas para resolver os problemas e demonstrando capacidade de manejo para lidar com seus filhos diante das circunstâncias estressoras surgidas diariamente no ambiente social (FRANCO, 2016).

Ademais, os cuidadores ou pais realizam maiores jornadas de trabalho para suprir todas as demandas da criança, diante do aumento de despesas, o que contribui para o aumento da sobrecarga física, para conseguirem inteirar com todas demandas existentes (GOMES et al., 2015).

Essa opção torna-se um fardo, pela sobrecarga com a dupla jornada e 0 encargo com o filho, mas que mesmo assim, é uma forma de enfrentar as dificuldades financeiras. Entretanto, os pais resistem de abdicar a vida 
profissional e tentam conciliar a profissão, as horas de trabalho no emprego, com os cuidados com o filho (MEIMES et al., 2015).

A sobrecarga dessa rotina implica em acumulo de emoções que são reprimidas, sejam elas por insuficiente apoio social e familiar, dificuldades financeiras, fadiga emocional e física, os quais se enquadram em fatores de adoecimento para esses pais ou cuidadores. Sendo assim, uma das maiores estratégias de enfrentamento devido a possibilidade de extravasamento de sentimentos é a pratica de exercícios físicos (KIM et al., 2018).

A pratica de exercícios físicos pode ser associada ou substituída pelo desenvolvimento de atividades alternativas, como ler, conversar, ver televisão, para, assim, poder desligar-se do foco estressor, pois muitas vezes falta-se tempo para atividades físicas (MACHADO; LONDERO; PEREIRA, 2018).

Outras estratégias utilizadas são o lazer e interação social, como um alivio para o sofrimento psicológico, mas, isso acabava implicando em aparecimentos de sentimento de culpa, pois planejar algo sem a presença da criança tornavase uma transgressão em relação ao seu papel de protetor (KIM et al., 2018).

Corroborando esse contexto, evidenciou-se que o ser, mãe, pai ou cuidador, sobrepõe-se ao ser individual com suas particularidades, arrumar-se para si, para seu companheiro e para suas atividades sociais ficam em segundo plano, pois sempre é presado atividades em grupo junto com a criança (ZANON; BACKES; BOSA, 2017).

\section{Conclusão}

Percebe-se que o estudo alcançou o objetivo proposto, cujas evidências apontam uma possível diminuição da qualidade de vida dos membros da família de crianças com TEA, visto a sobrecarrega física e emocional vivenciada especialmente pelos pais, diante do diagnóstico e da reestruturação dos arranjos familiares. Assim, as formas de enfrentamento são estratégias disparadoras utilizadas pelos familiares na busca por suprirem as demandas da criança, mas também as suas, enquanto ser humano e necessitado de cuidado. Todavia, esse enfrentamento vai depender da singularidade de cada indivíduo, para ser capaz de gerar uma melhoria na qualidade de vida deste e da família. 
Portanto, urge a necessidade de integração de políticas e programas que venham apoiar, empoderar e fortalecer familiares/cuidadores para uma vivência em equilíbrio com seu próprio "ser" frente ao cuidado da criança com autismo. Ademais, considerando a limitação no número de estudos que tratam sobre o tema, sugere-se a realização de novas pesquisas que possam ampliar o olhar para os pais de crianças com TEA, no intuído de evidenciar potencialidades e lacunas existentes no processo de cuidado à essa família pelos serviços da Rede de Atenção à Saúde para uma prática alicerçada na integralidade do cuidado.

\section{Referências}

BARDIN, L. Análise de conteúdo. São Paulo: 70. Ed. São Paulo: Martins Fontes, 2011. CANUT, A. C. A. et al. Diagnóstico Precoce do Autismo. Revista de Medicina e Saúde de Brasília, v. 3, n. 1, 2014. Disponível em: < https://portalrevistas.ucb.br/index.php/rmsbr/article/view/4254/3132>. Acesso em: 13 mar de 2019.

CONSTANTINIDIS, T. C.; SILVA, L. C. da; RIBEIRO, M. C. C. "Todo Mundo Quer Ter um Filho Perfeito": Vivências de Mães de Crianças com Autismo. Psico-USF, v. 23, n. 1, p. 47-58, 2018. Disponível em: < https://www.scielo.br/pdf/pusf/v23n1/2175-3563pusf-23-01-47.pdf>. Acesso em: 18 de Fev de 2020.

FRANCO, V. Tornar-se pai/mãe de uma criança com transtornos graves do desenvolvimento. Educar em Revista, n. 59, p. 35-48, 2016. Disponível em: https://www.redalyc.org/pdf/1550/155044835004.pdf. Acesso em: 18 de Fev de 2020.

GOMES, P. T. M. et al. Autism in Brazil: a systematic review of family challenges and coping strategies. Jornal de Pediatria (Versão em Português), v. 91, n. 2, p. 111-121, 2015. Disponível em: < https://cyberleninka.org/article/n/1384807.pdf>. Acesso em: 13 mar de 2019.

JOOSTEN, A. V.; SAFE, A. P. Management strategies of mothers of school-age children with autism: Implications for practice. Australian Occupational Therapy Journal, v. 61, n. 4, p. 249-258, 2014. Disponível em: < https://onlinelibrary.wiley.com/doi/abs/10.../1440-1630.12116>. Acesso em: 13 mar de 2019.

KIM, K. et al. Listening to the screaming whisper: a voice of mother caregivers of children with autistic spectrum disorder (ASD). International journal of qualitative studies on health and well-being, v. 13, n. 1, p. 1479585, 2018. Disponível em: < https://www.ncbi.nlm.nih.gov/pmc/articles/PMC6022232/>. Acesso em: 13 mar de 2019.

MACHADO, M. S.; LONDERO, A. D.; PEREIRA, C. R. R. Tornar-se família de uma criança com Transtorno do Espectro Autista. Contextos Clínicos, v. 11, n. 3, p. 335350 ,

2018.

Disponível

em: 
http://revistas.unisinos.br/index.php/contextosclinicos/article/view/ctc.2018.113.05.

Acesso em: 11 de Mai de 2020.

MINATEL, M. M.; MATSUKURA, T. S. Famílias de crianças e adolescentes com autismo: cotidiano e realidade de cuidados em diferentes etapas do desenvolvimento. Revista de Terapia Ocupacional da Universidade de São Paulo, v. 25, n. 2, p. 126-134, 2014. Disponível em: <https://www.revistas.usp.br/rto/article/view/65682>. Acesso em: 11 de Mai de 2020.

ONZI, F. Z.; DE FIGUEIREDO GOMES, R. Transtorno do Espectro Autista: a importância do diagnóstico e reabilitação. Revista Caderno Pedagógico, v. 12, n. 3, 2015.Disponível em:

http://univates.br/revistas/index.php/cadped/article/view/979/967>. Acesso em: 13 mar de 2019.

PISULA, E.; PORĘBOWICZ-DÖRSMANN, A. Family functioning, parenting stress and quality of life in mothers and fathers of Polish children with high functioning autism or Asperger syndrome. PloS one, v. 12, n. 10, p. e0186536, 2017. Disponível em: < https://journals.plos.org/plosone/article?id=10.1371/journal.pone>. Acesso em: 13 mar de 2019.

SANTOS, M. A. dos; PEREIRA-MARTINS, M. L. P. L. Estratégias de enfrentamento adotadas por pais de crianças com deficiência intelectual. Ciência \& Saúde Coletiva, v. 21, p. 3233-3244, 2016.Disponível em: <https://www.scielosp.org/pdf/csc/2016.v21n10/3233-3244/pt>. Acesso em: 26 out de 2019.

ZANON, R. B.; BACKES, B. BOSA, C. A. Diagnóstico do autismo: relação entre fatores contextuais, familiares e da criança. Revista Psicologia-Teoria e Prática, v. 19, n. 1, 2017.

Disponível em:

http://editorarevistas.mackenzie.br/index.php/ptp/article/view/8564>. Acesso em: 11 Mai de 2020. 